\title{
On the Collection Efficiency of Snow Crystals for Cloud Droplets
}

\author{
By Masahiro Kajikawa \\ Akita Technical College, Akita, Japan \\ (Manuscript received 27 November 1973, in revised form 5 March 1974)
}

\begin{abstract}
The collection efficiency of circular disks, hexagonal plates and plates with broad branches simulated to snow crystals for water droplets was experimentally obtained. The capture of supercooled droplets by the models of snow crystals was examined in the free falling state of them through a layer of droplets in order to make the experiment analogous to natural condition. The collection efficiency of natural snow crystals of hexagonal plate type was also obtained by the same method.

The collection efficiencies of models were generally smaller than Ranz and Wong's theoretical value based on the assumption of simplified flow around the circular disk except the region of their dimensionless parameter $\Psi \geq 0.9$, where $\Psi$ is a measure of the inertia of droplets. In the region of $\Psi \leq 1 / 16$, where the theoretical collection efficiency of circular disk becomes zero, experimental values were finite.

The collection efficiencies of natural snow crystals were smaller than values of models in the region of $\Psi>0.3$.
\end{abstract}

\section{Introduction}

The riming process including collection efficiency of the falling snow crystals for cloud droplets is important in studies of graupels and hails. The collection efficiency for bodies of ideal shapes, such as sphere, ribbon, cylinder and disk was studied theoretically or experimentally by many researchers. However, there are few istudies of the collection efficiency for body of complex shape such as snow crystals.

Kikuchi and Magono (1962) calculated the collection efficiency of snow crystals by using the observational data of size distribution of cloud droplets captured on snow crystals. Starr and Mason (1966) investigated the capture of pollen grains by snow crystal models. Observations of the onset of riming for ice crystals were reported by Ono (1969). Moreover, Sasyo (1971) and Sasyo and Tokuue (1973) studied the riming phenomena and collection efficiency for models of snow crystals which were fixed in a vertical wind tunnel.

On the other hand, theoretical estimation of the collection efficiency for sphere, cylinder and ribbon in potential flow was performed by Langmuir
andiBlodgett (1945). Ranz and Wong (1952) also calculated the collection efficiency of circular disk and ribbon. However, it is considered that the assumption of flow model involved in these estimation is not always valid to the flow field around snow crystals.

In this paper, the results of experimental studies are described on the collection efficiency of snow crystals. The capture of supercooled water droplets by the model or natural snow crystals was examined in free falling state of them, which was closely resembled to natural condition. The experimental values of collection efficiency were compared with the theoretical value of circular disk.

\section{Experimental technique}

The apparatus used for this experiment is shown in Fig. 1 and it was set in a cold room at $-22^{\circ} \mathrm{C}$. In the case of natural snow crystals, this apparatus was set in a snow igloo. Two vertical metal tubes, $85 \mathrm{~cm}$ and $1 \mathrm{~m}$ in length respectively, are separated by a shutter $\left(S_{1}\right)$. A few models of snow crystals are placed on a metal plate $\left(P_{1}\right)$ which is supported by an electric magnet. These models are made to fall by means of switching 


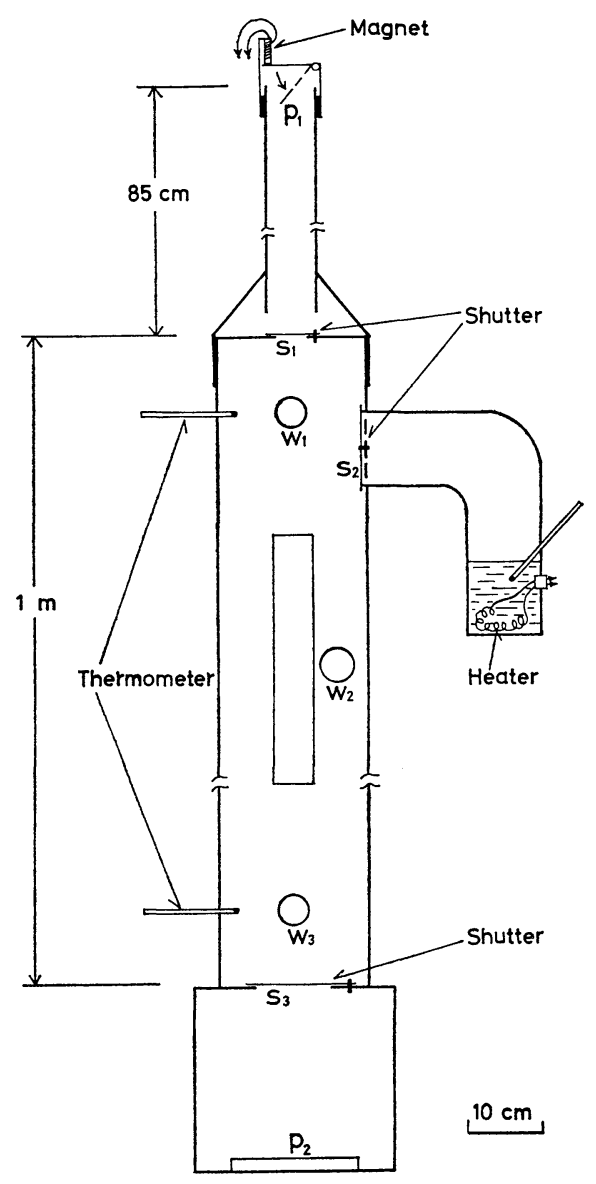

Fig. 1. Experimental apparatus.

off a electric circuit and then their velocities reach to terminal velocity during the fall through upper tube. The models enter into lower tube which is filled with supercooled droplets supplied from heated water (about $30^{\circ} \mathrm{C}$ ) and capture the droplets. The shutters $\left(S_{1}\right.$ and $\left.S_{3}\right)$ were opened only at the time of passing of the models, in order to prevent the turbulence of air in lower tube and to avoid the fall of droplets onto models on a sampling plate $\left(P_{2}\right)$. In the case of natural snow crystals, non-rimed crystals were made to fall into the inlet of upper tube. It was checked before experiment whether the crystals were rimed or not.

The models of snow crystals were made of a very thin printing film coated with the aqueous solution of water-blue (Okita, 1959) and a cellophane paper covered with the thin ice film. Fig. 2 is examples of the former. As seen in this figure, the models of three kinds, namely circular

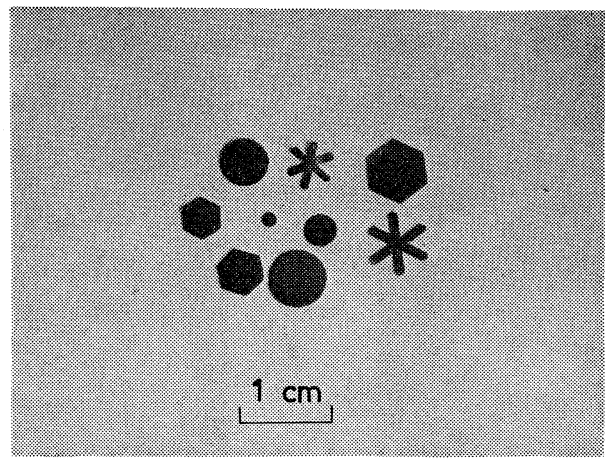

Fig. 2. Examples of model snow crystals.
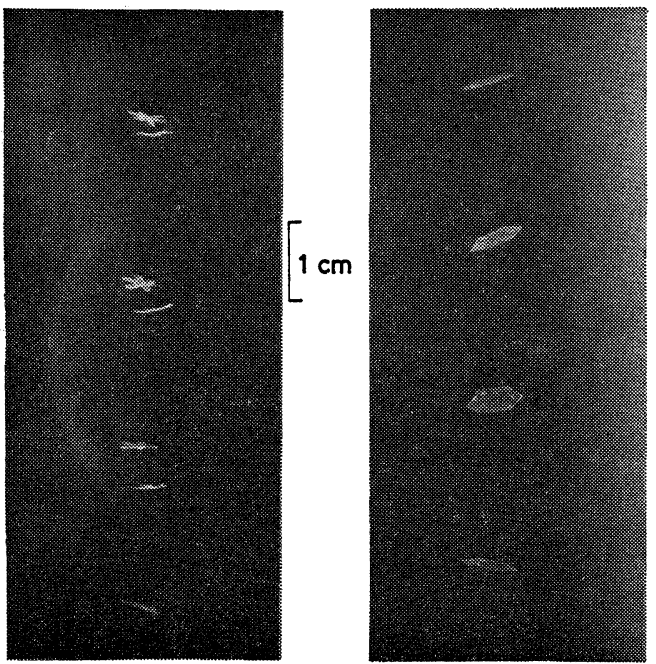

Fig. 3. Examples of stroboscopic photographs of falling models at $1 / 50$ sec intervals.

Left : plates with broad branches. Right: hexagonal plate.

disks, hexagonal plates and plates with broad branches, were prepared. The falling velocity of model crystals was measured by means of stroboscopic photographs, as seen in Fig. 3.

The size distribution of supercooled droplets was measured by impactor method (for example, Kuroiwa, 1957). The samplings of droplets were performed at three heights which are indicated by circles $\left(W_{1}, W_{2}\right.$ and $\left.W_{3}\right)$ in lower tube in Fig. 1. Two impactors with the caliber of $1 \mathrm{~mm}$ were used and the air which contained droplets of $10 \mathrm{cc}$ in volume was sucked with the rate of $20 \mathrm{cc} / \mathrm{sec}$ in order to make the collection efficiency of 1 to the droplets over $5 \mu$ in diameter. Solid line in Fig. 5 is an example of size distribution of droplets in the condition of about 15 minutes, 

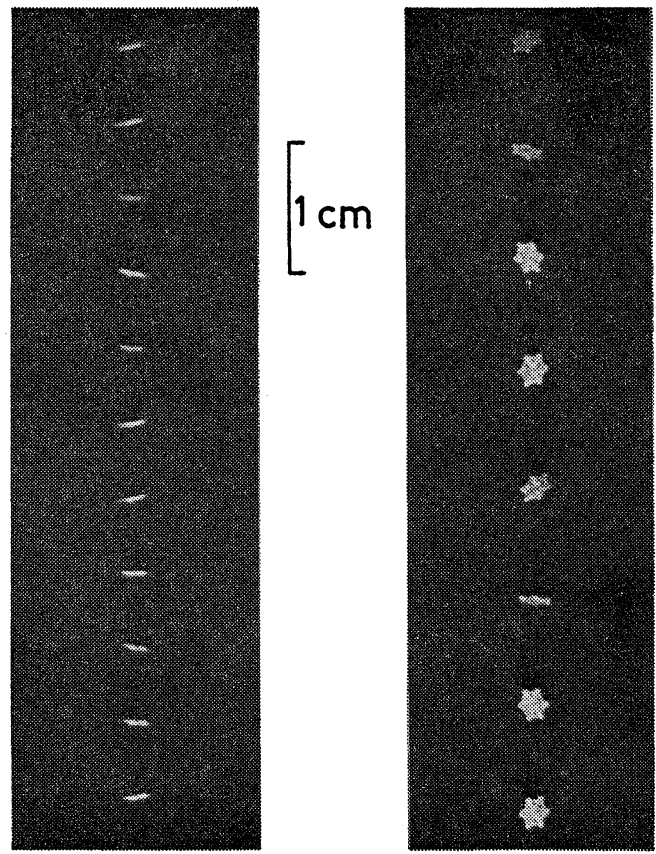

Fig. 4. Examples of stroboscopic photographs of falling snow crystals at $1 / 100 \mathrm{sec}$ intervals.

Left : dendritic crystal with plates at ends.

Right: Rimed stellar crystal.

after shutter $\left(S_{2}\right)$ was opened and droplets were supplied to lower tube. The time required for the air in lower tube to be stable was about 15 minutes in this experiment. Sampling positions are referred in the left bottom of the figure. It can be considered that the numbers of droplets in middle part virtually show mean values in the lower tube because similar tendency was seen also in another measurements. Therefore, in the ordinaly case the sampling of droplets was performed at the middle part of tube.

Broken and dotted line in Fig. 5 are size distribution of droplets at the state of about 20 and 30 minutes after the shutter $\left(S_{2}\right)$ was opened, respectively. To indicate the amount of scatter in size distribution at the same condition (elapsed time and temperature of cold room and heated water), standard deviations are shown also in this figure. Although the concentration of large droplets gradually increased as the time proceeds, the size distribution was considerably stable at the same condition.

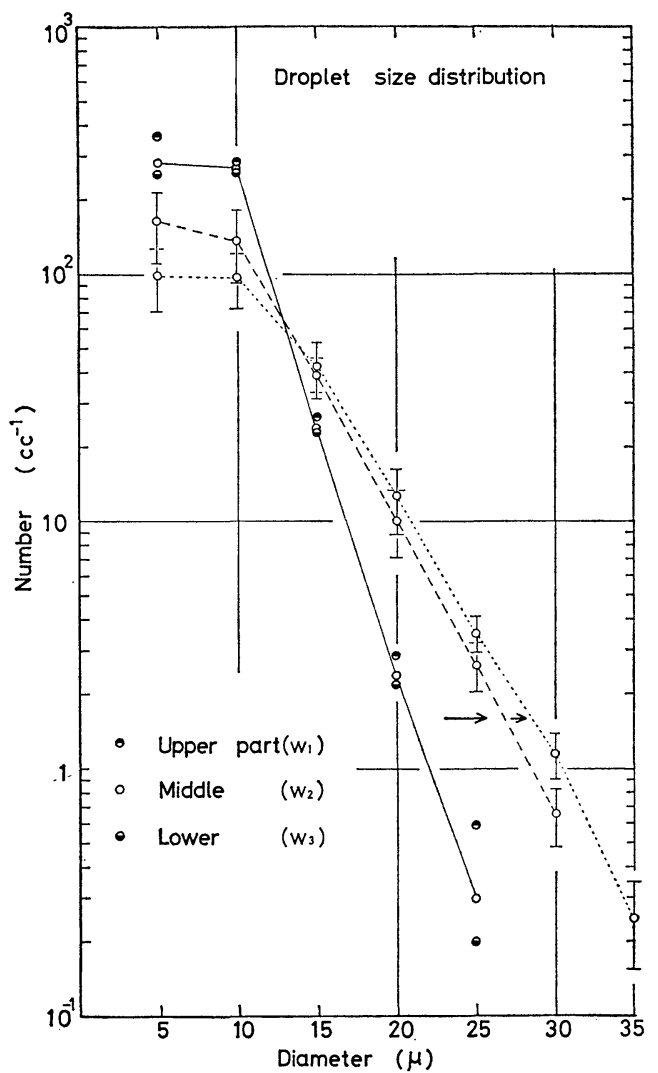

Fig. 5. The size distribution of supercooled water droplets. Solid line is the state of 15 minutes and broken line and dotted line are mean values of the state of 20 and 30 minutes after the shutter $\left(S_{2}\right)$ was opened, respectively.

\section{Results}

\section{1. Collection efficiency of model snow crystals}

Examples of model snow crystals which captured supercooled droplets are shown in Fig. 6. The upper picture (a) is a circular disk $(1.4 \mathrm{~mm}$ in diameter, $55 \mu$ in thickness) which is made of a piece of cellophane paper covered with thin ice film. The lower picture (b) is a plate with broad branches $(5.0 \mathrm{~mm}$ in diameter, $20 \mu$ in thickness) which is made of very thin film coated by waterblue dye. It can be seen that the captured droplets distribute at the edge or the branches of models.

The size distribution of droplets obtained by impactor method and captured droplets on the disk of Fig. 6-a are shown in Fig. 7. The numbers of captured droplets were counted regardless of front and rear surface of models or natural 


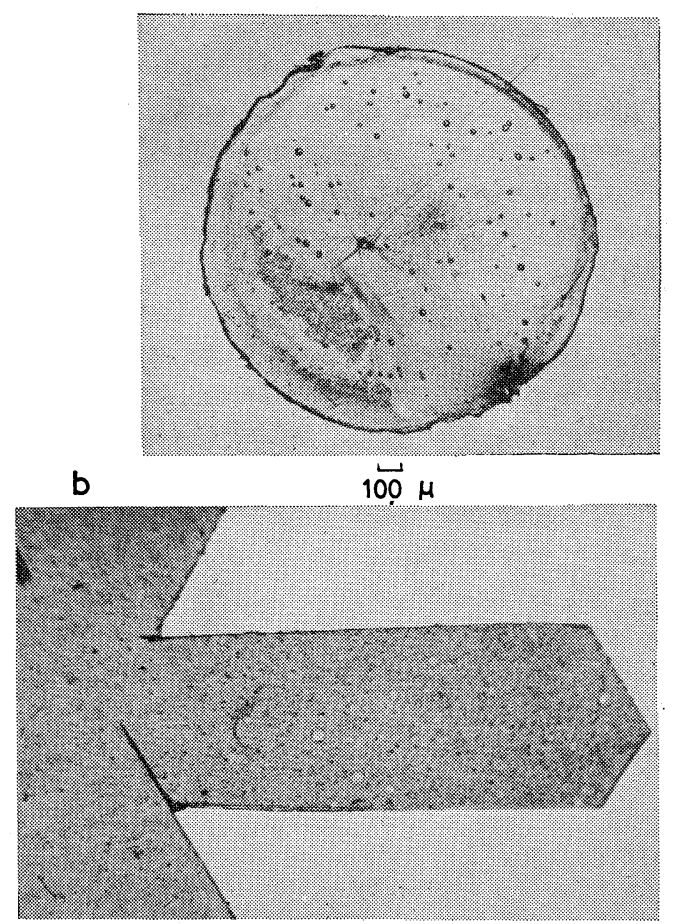

Fig. 6. Examples of the models captured droplets. In picture (b), the dark rings are traces of captured droplets.

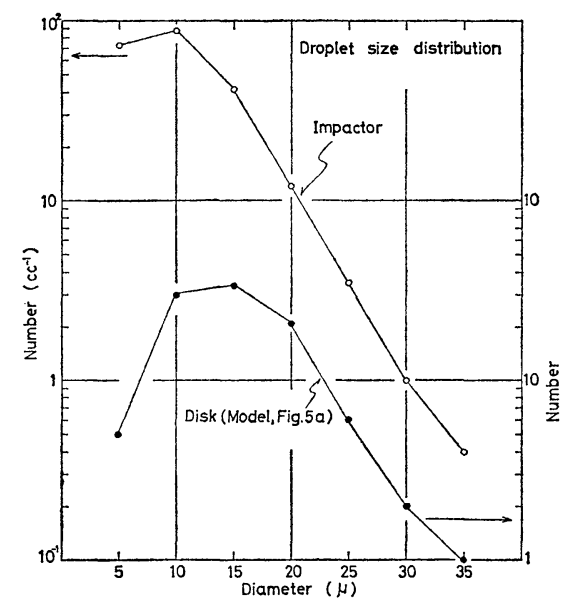

Fig. 7. The size distribution of droplets in the case of circular disk of Fig. 6-a.

snow crystals, because the strict distinction between the captured droplets on front surface and on rear surface was difficult in this experimental method.

The collection efficiency was calculated from the following formula. For example, when a circular disk of diameter $\left(D_{c}\right)$ is falling through a cloud layer, the number $(N)$ of collected droplets during the fallen time $(t)$ is given by

$$
N=\frac{\pi}{4} E\left(D_{c}+D_{p}\right)^{2} n\left(V_{0}-v\right) t
$$

where $E$ is the collection efficiency of the disk for the droplet of diameter $\left(D_{p}\right), n$ the spatial concentration of droplets in the cloud layer, $V_{0}$ the falling velocity of disk and $v$ the falling velocity of droplets. In this formula, it is assumed that models or natural snow crystals fall in a fixed orientation with plane horizontal. Although the attitude of actual motion is not always stable as seen in Figs. 3 and 4, the following calculations were performed under the assumption that models or snow crystals fell in a fixed orientation. It is considered from these figures that the attitude of falling models and natural snow crystals is considerably similar.

The obtained collection efficiency (mean value) of circular disk is shown in Fig. 8, with standard deviation. These values were obtained every $5 \mu$ in width of droplet diameter, on various diameters and velocities of circular disks. The diameter and velocity of disk are given in the right bottom of figure. Solid and broken lines show the collection efficiency obtained by cellophane and film models, respectively. It appears from this figure that the collection efficiency increases obviously with the

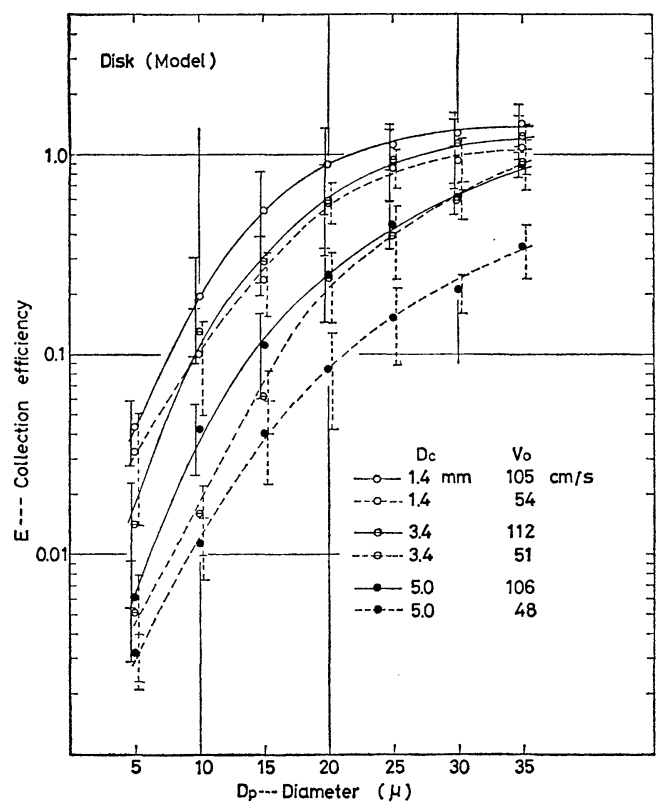

Fig. 8. The collection efficiencies of circular disks. 
increase of droplet diameter and that it decreases with the increase of disk diameter if falling velocity is approximately equal. The same tendencies of collection efficiency for hexagonal plate model and plate with broad branches model are seen in Fig. 9 and Fig. 10, respectively. In several cases of this experiment, collection efficiencies were larger than 1. The reasons of this result may be considered as follows. Because the number of

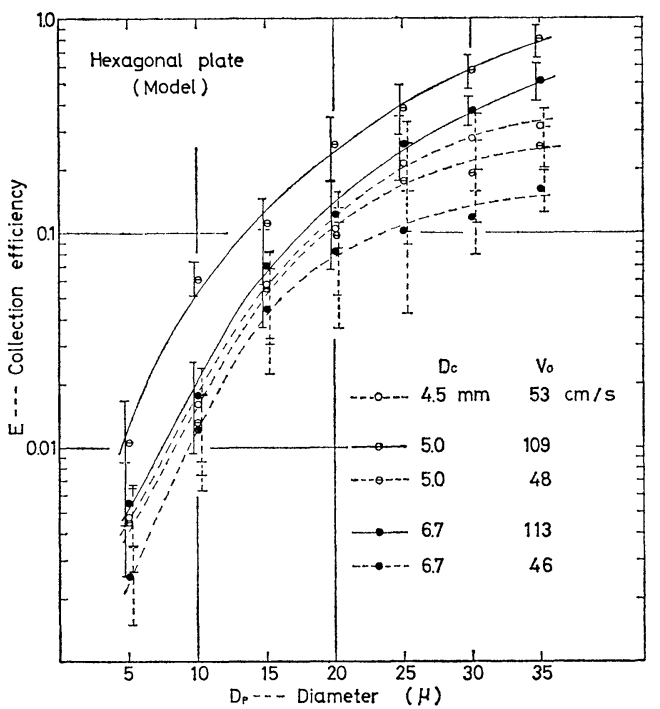

Fig. 9. The collection efficiencies of hexagonal plates.

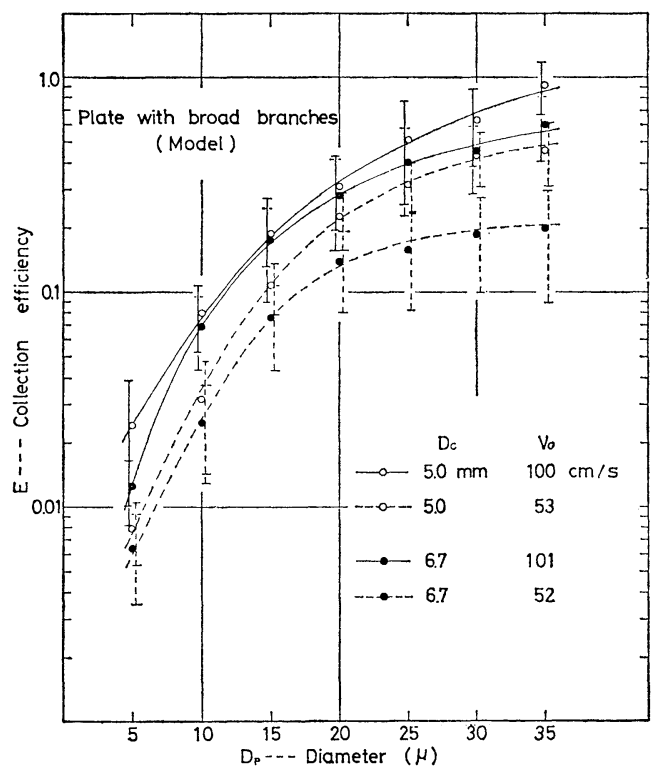

Fig. 10. The collection efficiencies of plates with broad branches. captured droplets were counted regardless of front and rear surface of models, the captured droplets in the wake of models are involved in the number $(N)$. Moreover, the influence of unstable motion (pitching or tumbling motion) of models at the falling state is considered, since the fall path of models in cloud layer becomes complicated or increases as a result of these motions.

Comparisons of collection efficiencies of different shapes with the same diameter $(5 \mathrm{~mm})$ and approximately the same velocity $(1 \mathrm{~m} / \mathrm{sec})$ are shown in Fig. 11. It can be seen that the collection efficiency of plane with broad branches is generally larger than that of other shapes. The efficiency of hexagonal plate is slightly larger than that of circular disk in the region of smaller droplets. The same tendency of collection efficiency was seen also in the case of falling velocity about $50 \mathrm{~cm} / \mathrm{sec}$.

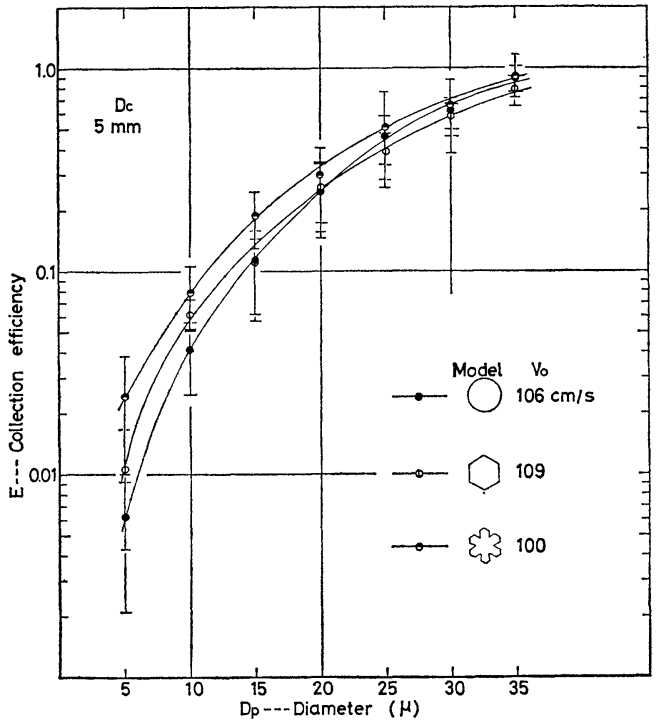

Fig. 11. Comparisons of collection efficiencies of different shape models.

\subsection{Collection efficiency of natural snow crystals}

The experiment was performed in a snow igloo near the top of Mt. Teine (1023 m m.s.l.), utilizing an apparatus of the same as shown in Fig. 1.

An example of snow crystals which captured supercooled droplets is shown in Fig. 12. The size distributions of the captured droplets on snow crystal and the supercooled droplets measured by impactor method are also shown in the same 


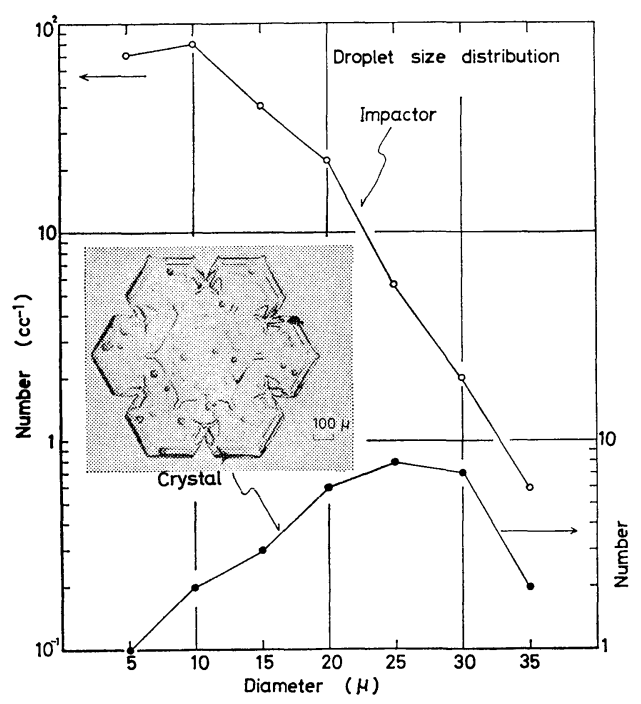

Fig. 12. An example of the size distribution of droplets captured by a natural snow crystal (hexagonal plate).

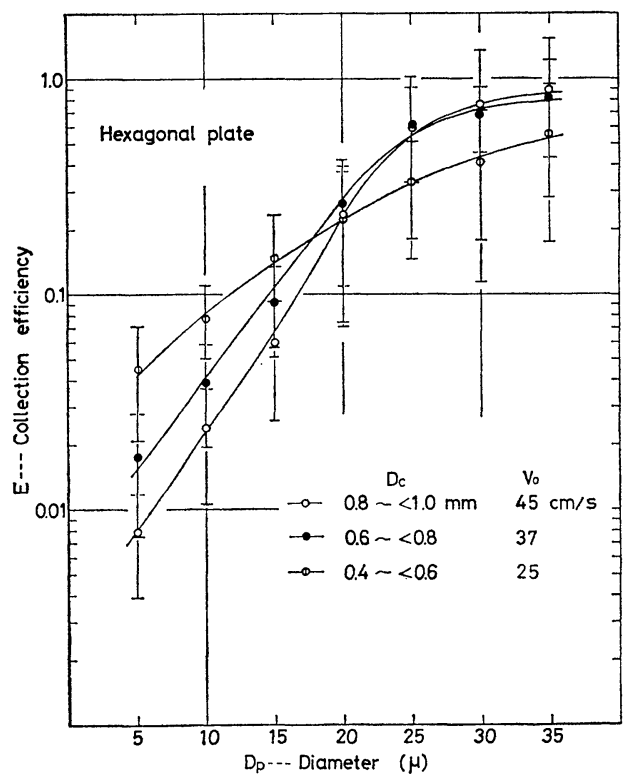

Fig. 13. The collection efficiencies of natural snow crystals (hexagonal plates).

figure. It can be seen that the collection efficiency becomes larger in the region of larger droplets. Fig. 13 is the mean collection efficiency of hexagonal plates for droplets of various sizes. Although the several cases of no captured droplets were existent in the region of larger droplets, where the spatial concentration of droplets is small, the collection efficiencies of these cases were regarded to be zero. The sizes and falling velocities of snow crystals are given in the right bottom in this figure. The falling velocity of those crystals was decided from the measurement of Kajikawa (1972). In this figure, the snow crystals, which have the spreading feature of captured droplets as described by Macklin and Payne (1969), are removed from the data of measurement of collection efficiency.

It appears from this figure that the collection efficiency of hexagonal plate increases with the decreases of diameter of crystals in the region of smaller droplets. On the other hand, in the region of larger droplets the decrease of efficiency is seen with the decrease of diameter of crystals. In several cases of plane crystals of diameter 280$390 \mu$, the numbers of captured droplets were a few. This tendency agrees with the result of Ono (1969), who ovserved the riming is rare on plates $<300 \mu$ in diameter.

\section{Discussion}

There are practically no theoretical calculations of collection efficiency available for comparison with the result of this experiment in the same range of Reynolds number (Re). However, the comparison with theoretical value calculated by Ranz and Wong (1952) may be significant. They obtained the collection efficiency of circular disk under the assumption of simplified flow. In this flow model, it was assumed that velocity field near the stagnation point is linear function of position.

This theoretical value by them, the experimental values by the author and the experimental values by Starr and Mason (1966) and Sasyo and Tokuue (1973) are shown in Fig. 14 as a function of dimensionless number $\Psi$ defined by Ranz and Wong (1952) as follows.

$$
\Psi=\left(C \rho_{p} V_{0} / 18 \mu D_{c}\right) D_{p}^{2}
$$

where $C$ is the empirical correction factor for resistance of a gas to movement of small particles (the value of $C$ in this experiment can be considered to be 1$), \rho_{p}$ the density of droplets, $V_{0}$ the falling velocity of models or snow crystals, $\mu$ the viscosity of air, $D_{c}$ the diameter of models or snow crystals and $D_{p}$ the diameter of droplets. The physical meaning of $\Psi$ is considered to be concerned with the inertia of droplets.

It may be better that the comparison or discussion of collection efficiency is made in following three ranges of $\Psi$, namely, the ranges of greater 


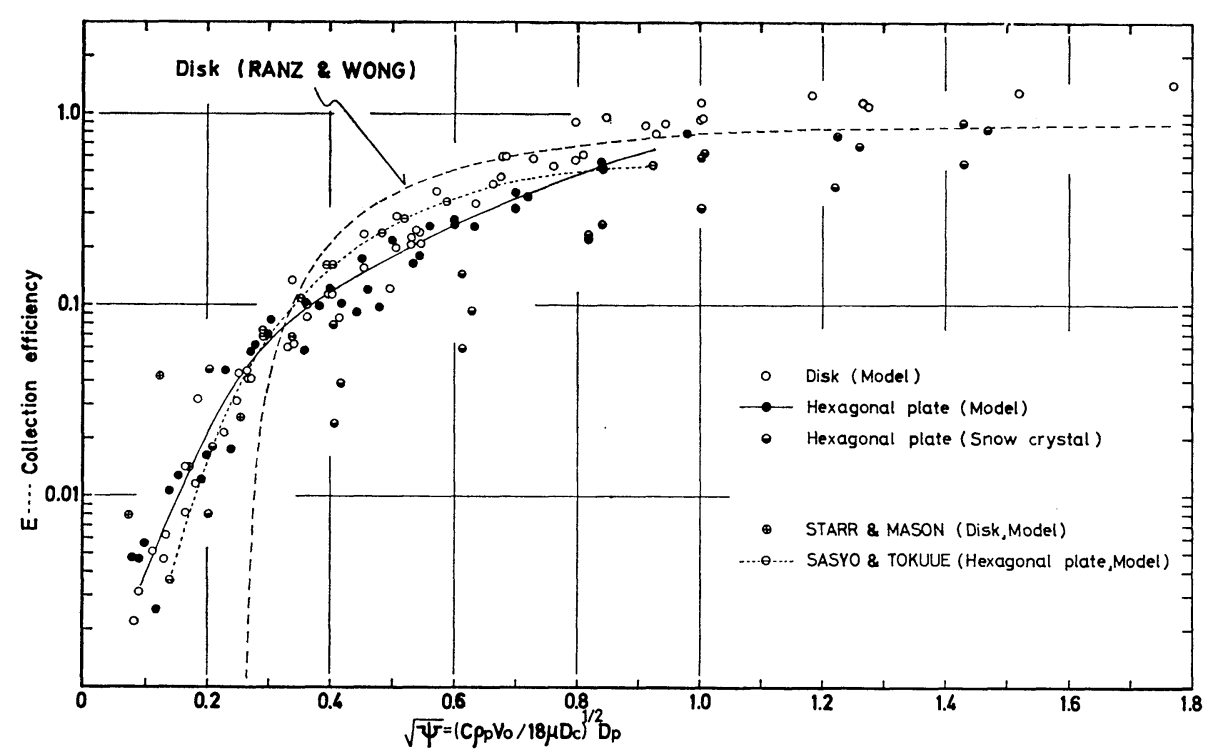

Fig. 14. Theoretical and experimental values of the collection efficiency $v s$ dimensionless number $\Psi$ defined by Ranz and Wong (1952).

than 0.9 , between 0.3 and 0.9 and smaller than 0.3 . In the range of large $\Psi$, the theoretical value by Ranz and Wong approximately coincide with the results of present experiment. However, this theoretical value is generally larger than the experimental values in the range of medium $\Psi$. Kikuchi and Magono (1962) were mentioned according to the observation of cloud droplets collected by snow crystals that the collection efficiency of crystals seemed to be much smaller than the theoretical value. Their conclusion is qualitatively coincident with the above-mentioned result of present experiment. In the range of small $\Psi$, where Ranz and Wong's theoretical value becomes approximately zero, the experimental results have finite values.

The reasons of those discrepancies between theoretical and experimental value may be considered as follows.

(1) The difference of Re comes up as an important problem. Namely, the difference of flow pattern (in other words, velocity field around models or snow crystals) exist between the theoretical calculation and the circumstances of experiment.

(2) Influence of unstable motion (pitching or tumbling motion) of models at the falling state. It is considered that the unstable motion occurs at $\mathrm{Re}$ greater than about 100 and the grade of unstable motion also depends on moment of inertia of models
(Willmarth et al., 1964).

(3) Influence of the dimension of droplets, in particular, in the case of small crystals, because the dimension of droplets against that of circular disk is neglected in the theoretical calculation.

Moreover, the collection efficiency of natural snow crystals (hexagonal plate type) is considerably smaller than that of hexagonal plate models (solid line in Fig. 14), in the same values of $\Psi$. This fact indicate that the flow pattern of both was not similar, since $\mathrm{Re}$ of hexagonal plate models was different from that of snow crystals. $\operatorname{Re}$ of this experiment is shown in Table 1. In the case of hexagonal plate model, the collection

Table 1. Range of Reynolds number (Re) in the experiment

\begin{tabular}{l|r}
\hline \multicolumn{1}{c|}{ shape } & \multicolumn{1}{c}{ Re } \\
\hline circular disk (model) & $64-506$ \\
plate with broad branches (model) & $223-575$ \\
hexagonal plate (model) & $200-640$ \\
\hline hexagonal plate (snow crystals) & $10-36$ \\
\hline
\end{tabular}

efficiency is affected significantly by unstable motion at the falling state because $\mathrm{Re}$ is larger than 200. On the other hand, in the case of snow crystals it can be considered that there is no effect of unstable motion because $\operatorname{Re}$ is smaller than 36 .

The results of experiment by Starr and Mason 
(1966) utilizing snow crystal models, as seen in Fig. 14, are approximately coincidence with the present experiment. $\operatorname{Re}(25$ to 157 ) in their experiment is similar to that of the present experiment. The experimental result of Sasyo and Tokuue (1973), utilizing the fixed models of hexagonal plate in a vertical wind tunnel, is shown by dotted line in Fig. 14. A certain degree of systematic discrepancy is in existence between their result and the value of hexagonal plate models in present experiment. It is considered that this discrepancy is mainly due to the reasons of (1) and (2) as mentioned above since their experiment is performed involving the region of large $\mathrm{Re}$ in comparison with present experiment. However, it is qualitatively analogous to the present experiment that the collection efficiency by them has the finite value in the range of small $\Psi$.

\section{Concluding remarks}

The collection efficiency of snow crystal models and natural snow crystals was experimentally obtained. A summary of the results is shown below. In the range of $\Psi \geq 0.9$, where the parameter $\Psi$ is a measure of the inertia of water droplets, the results of present experiment and theoretical calculation of Ranz and Wong (1952) were roughly coincident with each other. In the range of $\Psi \leq 1 / 16$, where the theoretical value becomes zero, the experimental results had finite values. In the range of medium $\Psi$, the experimental values were generally smaller than theoretical one at the same values of $\Psi$. It is considered that this discrepancy was caused by the difference of velocity field between simplified flow in the theoretical calculation and actual flow around the models or snow crystals. The collection efficiency of snow crystals (hexagonal plate) was smaller than that of hexagonal plate models at the same values of $\Psi$. This fact indicates that $\operatorname{Re}$ is very important factor for the estimation of collection efficiency of snow crystals in addition to $\Psi$. When $\Psi$ and $\mathrm{Re}$ is the same values, the result of present experiment might be applied to natural condition of riming process.

\section{Acknowledgements}

This paper is based on a part of the thesis for a doctor's degree of Department of Geophysics, Hokkaido University, under Prof. C. Magono. The author expresses hearty thanks to him. The author is also grateful to the members of Cloud Physics Group in his laboratory for their supports of the experiment at the Mt. Teine. The expense of this work was supported by scientific research fund from the Education Ministry of Japan.

\section{References}

Kajikawa, M., 1972: Measurement of falling velocity of individual snow crystals. J. Meteor. Soc. Japan, 50, 577-584.

Kikuchi, K. and C. Magono, 1962: On the collecting efficiency of cloud particles by snow crystals. $J$. Japan. Soc. Snow and Ice, 24, 67-80.

Kuroiwa, D., 1957: Studies on physical and chemical properties of sea-fog nuclei and maritime aerosols by means of an electron microscope. Low Temperature Science, Ser. A, 16, 79-117.

Langmuir, I. and K. B. Blodgett, 1945: A mathematical investigation of water droplets trajectory. Collected works, Pergamon Press, London, 10, 417.

Macklin, W. C. and G. S. Payne, 1969: The spreading of accreted droplets. Quart. J. Roy. Meteor. Soc., 95, 724-730.

Okita, T., 1959: Water-blue film method for measurement of cloud and fog droplets. J. Meteor. Soc. Japan, 37, 42-43.

Ono, A., 1969: The shape and riming properties of ice crystals in natural clouds. J. Atmos. Sci., 26, 138-147.

Ranz, W. E. and J. B. Wong, 1952: Impaction of dust and smoke particles on surface and body collectors. Ind. Eng. Chem., 44, 1371-1381.

Sasyo, Y., 1971: Study of the formation of precipitation by the aggregation of snow particles and the accretion of cloud droplets on snowflakes. Pap. Met. Geophys., 22, 69-142.

and H. Tokuue, 1973: The collection effciency of simulated snow particles for water droplets (preliminary report). Pap. Met. Geophys., 24, 1-12.

Starr, J. R. and B. J. Mason, 1966: The capture of airborne particles by water drops and simulated snow crystals. Quart. J. Roy. Meteor. Soc., 92, 490-499.

Willmarth, W. W., N. E. Hawk and R. L. Harvey, 1964: Steady and unsteady motions and wakes of freely falling disks. Phys. Fluids, 7, 197-208. 


\title{
雪結晶の雲粒捕捉率について
}

\author{
梶川 正弘 \\ 秋田工業高等専門学校
}

雪結晶の雲粒捕捉率を実験的に決めることを試みた。できるだけ天然の状態に近づける意味で, 微水滴を含む空気 層中を模型雪（形は円板，六角板，広幅六花状の三種）や雪結晶（雲粒の付着していない角板）を，自由落下させる 方法が用いられた．それらの結果を Ranz と Wong の理論計算による円板の捕捉率と比較した，彼等の定義した無 次元パラメータ $\Psi$ が 0.9 以上の範囲を除き，模型雪の実験值は理論值より小さかった。 また角板結晶の捕捉率は, 模型角板のそれよりも同じ $\Psi$ のところで小さかった，さらに，理論計算による捕捉率がゼロとなる範囲 $(\Psi \leq 1 / 16)$ で, 実験值は有限の值となった。 これらの結果から，雪結晶の捕捉率は $\Psi$ に加えて特にレイノルズ数にも左右され ると考えられる. 